\title{
Chronic Spontaneous Urticaria: A Review of Pathological Mechanisms, Diagnosis, Clinical Management, and Treatment
}

Our Editor's Pick for this EMJ flagship is the review paper by Mandel et al. Chronic spontaneous urticaria has received a lot of attention recently as researchers have aimed to become more knowledgeable on this little-known condition. Despite this, the authors provide a positive summary of the promising treatment options currently being developed, as well as a detailed breakdown of the existing diagnosis methods and clinical management. This is a timely review article, as several new-generation biological drugs to treat this disease are now entering clinical trials.

Authors:

*Victor Desmond Mandel,,2 Tatiana Alicandro, ${ }^{3}$ Patrizia Pepe, 1,3 Laura Bonzano, ${ }^{3}$ Mario Bruno Guanti, ${ }^{3}$ Pietro Andreone, ${ }^{4}$ Giovanni Pellacani ${ }^{1}$

1. Dermatology Unit, Surgical, Medical, and Dental Department of Morphological Sciences Related to Transplant, Oncology and Regenerative Medicine, University of Modena and Reggio Emilia, Modena, Italy

2. Dermatology Unit, Department of Clinical and Experimental Medicine, University of Parma, Parma, Italy

3. Allergology Unit, Surgical, Medical and Dental Department of Morphological Sciences Related to Transplant, Oncology and Regenerative Medicine, University of Modena and Reggio Emilia, Modena, Italy

4. Division of Internal Medicine, Department of Medical and Surgical Sciences, Maternal-Infantile and the Adult, University of Modena and Reggio Emilia, Modena, Italy

*Correspondence to victor.desmond.mandel@gmail.com

Disclosure:

Acknowledgements:

Received:

Accepted:

Keywords:

Citation:
The authors have declared no conflicts of interest.

Honorarium, grant, or other form of payment, were not given to anyone of the authors to produce the manuscript. All authors made substantive intellectual contributions to the published study and each author listed on the manuscript has seen and approved the submission of the manuscript. The authors would like to thank Johanna Chester for her linguistic supervision and critical revision. Victor Desmond Mandel and Tatiana Alicandro equally contributed to this manuscript and should be considered co-first authors.

04.09.19

03.01 .20

Angioedema, chronic spontaneous urticaria, histamine antagonists, omalizumab, urticaria, vascular skin diseases.

EMJ. 2020;5[1]:29-39.

\section{Abstract}

Urticaria is a poorly understood and underestimated clinical condition characterised by the sudden onset of itchy wheals and/or angioedema, which usually resolve within 24 and 72 hours, respectively. It is generally classified as being acute (lasting $<6$ weeks) or chronic (continuous or intermittent for 
$\geq 6$ weeks). Chronic urticaria can be further classified as chronic spontaneous urticaria (CSU) and chronic inducible urticaria, appearing in response to specific eliciting factors, such as heat, cold, or sun exposure, or following the application of pressure. Scientific advances have been made in the understanding of pathological mechanisms and treatment, especially associated with CSU. The exact pathological mechanism of how urticaria develops is still not yet fully understood, but the clinical implications on the patients' quality of life are severe and have been associated with mental disorders and metabolic diseases. The diagnosis of urticaria is based on medical history and clinical manifestations. The treatment pathway begins with the administration of second-generation, nonsedating, nonimpairing histamine 1 receptor antihistamines and, in case of nonresponse, with new-generation biological drugs. The current review presents an update of the pathological mechanisms, diagnosis, clinical management, and treatment of CSU. It also focusses on the future implications of new-generation drugs and their effects on the clinical practice.

\section{INTRODUCTION}

Urticaria is a common mast cell-driven disease characterised by wheals and/or angioedema (Figure 1), defined as chronic when symptoms occur continuously or intermittently for $\geq 6$ weeks and as spontaneous when specific eliciting stimuli, such as thermal agents, vibration, cholinergic factors, aquagenic, and delayed pressure, have been excluded as possible triggers.' When symptoms last $<6$ weeks, a diagnosis of acute urticaria can be made, and when the above mentioned triggers are identified, a diagnosis of chronic inducible urticaria is assigned. ${ }^{1}$ Urticaria has a strong impact on patients' quality of life, and has been associated with anxiety, depression, somatoform disorders, metabolic syndrome, obesity, and sleep difficulties. ${ }^{2-4}$ Patients can also present associated clinical symptoms, such as joint pain, headache and fatigue, flushing, breathlessness, gastrointestinal symptoms, and palpitations. ${ }^{5}$ The prevalence of acute urticaria is assessed to be 2-fold higher than chronic urticaria. ${ }^{1}$ Approximately $50 \%$ of cases of acute urticaria are idiopathic (i.e., a specific trigger is not identified) and this condition, which is referred to as acute spontaneous urticaria, can progress to chronic spontaneous urticaria (CSU) in up to $36 \%$ of patients. ${ }^{6,7}$ Chronic urticaria is considered more common in adults, with a peak age of onset between 20 and 40 years, and women are affected twice as often as men., ${ }^{6,8}$ Two recent studies, however, suggested that the prevalence of chronic urticaria and CSU in the paediatric population is similar to that of the adult population. 9,10 Urticaria cases in children and in adolescents might be treated by parents using over-the-counter medications and can possibly explain this underestimation in different studies. ${ }^{9}$

The average duration of chronic urticaria is 3-5 years ${ }^{11}$ and its prevalence has been estimated to be $0.5-5.0 \%$, $^{12}$ while CSU affects approximately $0.5-1.0 \%$ of the global population. ${ }^{13}$

Scientific advances have been made in the understanding of pathological mechanisms and treatment, especially associated with CSU. The current review presents an update of the pathological mechanisms, diagnosis, clinical management, and treatment of CSU. It also focusses on the future implications of new-generation drugs and their effects on the clinical practice.

\section{PATHOLOGIC MECHANISMS}

The pathogenesis of CSU is complex and many different factors have been proposed as possible triggers including infections, food and drugs allergies, and genetic factors such as human leukocyte antigen Class II alleles associated with autoimmunity and the coagulation cascade. However, these proposed triggers have not been proven to be the causal immunologic mechanism, which today still remains unknown. ${ }^{1}$ Nevertheless, a strong association is found between CSU and major autoimmune diseases, including autoimmune thyroid diseases, rheumatoid arthritis, Sjögren syndrome, coeliac disease, Type I diabetes mellitus, and systemic lupus erythematosus, ${ }^{14}$ and there is evidence pointing towards a potential autoimmune aetiology in $\leq 50 \%$ of patients with CSU. ${ }^{15}$ 

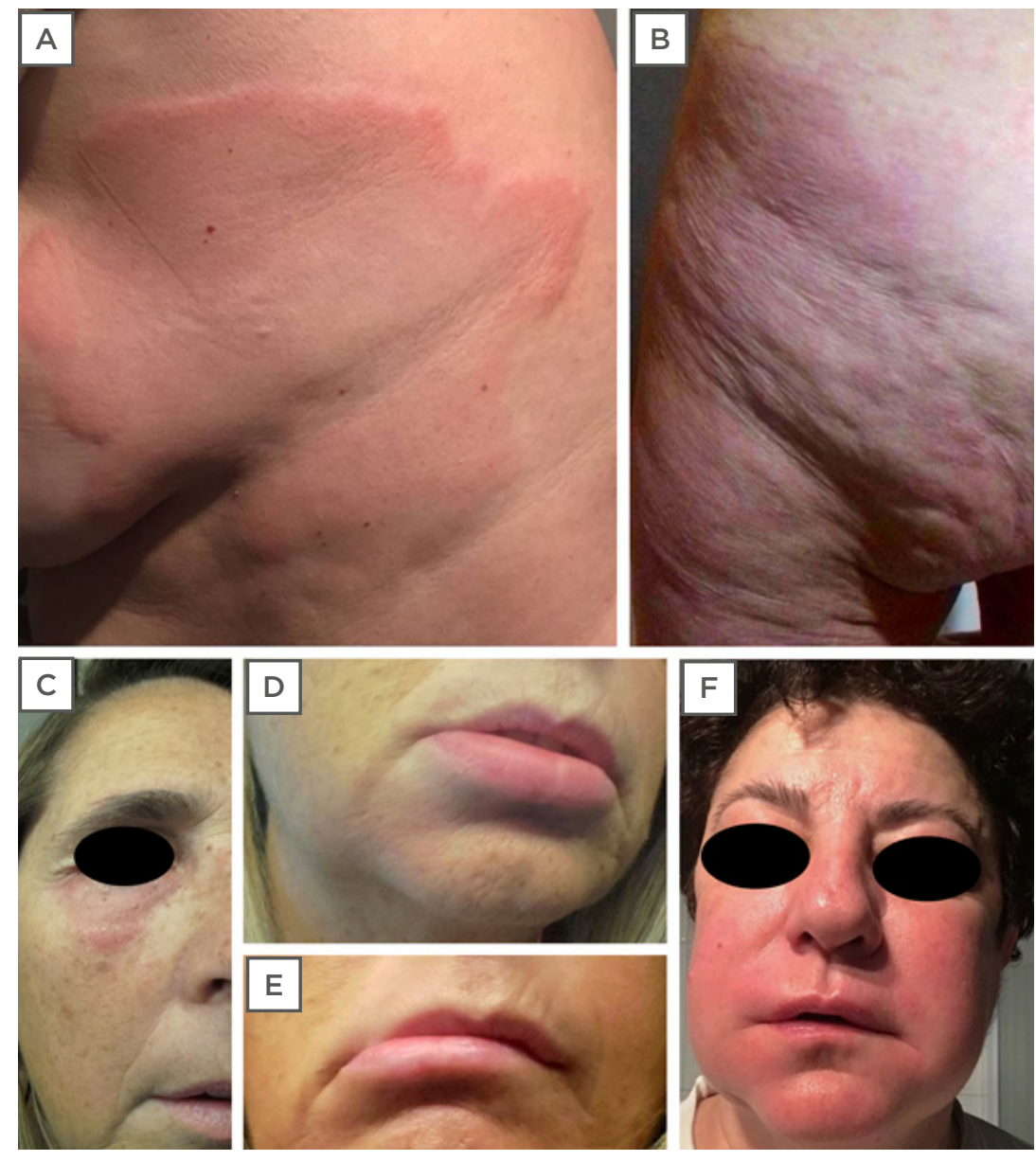

Figure 1: (A-B) Urticaria is characterised by an outbreak of swollen, pale red bumps or plaques on the skin (wheals). (C-F) Urticaria can also manifest as deep swelling around the eyes, lips, and face (angioedema) that appears suddenly.

At histological evaluation, wheals and Specifically associated with CSU, some angioedema present features common to authors have demonstrated that upregulation inflammation including the vasodilatation of of adhesion molecules for eosinophil cells, in postcapillary venules, oedema, and a cellular infiltrate characterised by mast cell degranulation and migration of CD4+ Tlymphocytes, monocytes, neutrophils, eosinophils, and basophils. ${ }^{16}$ The oedema develops in the upper- and mid-dermis in the form of wheals, while angioedema involves the subcutaneous or submucosal tissue. ${ }^{1}$ Cutaneous mast cells play a key role in CSU because their degranulation leads to the relapse of histamine; different proinflammatory cytokines, such as IL-1, IL-4, IL-5, IL-6, IL-8, and TNF-a; plateletactivation factor; vascular endothelial growth factor; matrixmetalloproteinase-9; neuropeptides; and other vasoactive substances. ${ }^{5}$ This is a standard inflammatory mechanism common to particular P-selectin, alters cytokine expression and microvascular changes in nonlesional skin, and additionally alters the detection of blood basophils in lesional skin exhibiting suppressed IgE receptors, responsible for the release of histamine and upregulation of its release by IL-3. ${ }^{17-19}$

The recruitment of basophils into wheals results in blood basopenia. ${ }^{20}$ Following successful treatment, CSU remission has been associated with an increase in blood basophil numbers and IgE receptor-triggered histamine response. ${ }^{20-22}$ The IgE receptor-triggered histamine response is also observed during anti-lgE treatment. many inflammatory diseases. 
It has also been suggested that autoimmunity could be relevant for mast cell activation, specifically for some types of immunological mechanisms. ${ }^{23}$ Hypersensitivity reactions have been classified into four types (I-IV) according to immunological mechanisms (Gell and Coombs classification of hypersensitivity reactions). ${ }^{24}$ Type I hypersensitivity is due to the presence of an allergen that binds IgE, present on mast cell and basophil surfaces. This link induces the degranulation of the mast cells and basophils, and the release of mediators. Type II is mediated by antibodies, typically IgG or IgM, which link either IgE and/or high affinity IgE receptor (FceRI) on mast cells and basophils or low-affinity IgE receptor (FcERII) on eosinophils leading to vasoactive mediator release. ${ }^{23}$

The coagulation cascade has also been hypothesised as a possible CSU immunologic mechanism. ${ }^{25}$ In fact, it has been observed that some CSU subjects have high levels of D-dimer, secondary to activation of the coagulation cascade by the activated eosinophils hyperexpressing tissue factor and other activated coagulation factors that amplify the release of histamine from mast cells and basophils. ${ }^{26}$ Another possible immunological mechanism recently studied is the endocrine abnormalities of fatty tissue in overweight CSU patients. The fatty tissue may lead to the production of several adipokines that directly target human mast cells and also play a role in endothelial inflammation leading to the production of atherosclerotic plaque. ${ }^{27}$ Chronic inflammatory skin diseases are known to be a risk factor for metabolic syndromes, and patients with metabolic syndromes and CSU exhibit high levels of prothrombin fragment $1+2$, D-dimer, and inflammatory markers such as IL-6, IL-1, TNF-a, and C-reactive protein. ${ }^{28}$

\section{DIAGNOSIS AND CLINICAL MANAGEMENT}

According to the European Academy of Allergology and Clinical Immunology (EAACI), the European Union (EU)-founded network of excellence, the Global Allergy and Asthma European Network (GA $\left.{ }^{2} L E N\right)$, the European Dermatology Forum (EDF), and the World Allergy Organization (WAO) guideline, diagnostic work-up starts from medical history and physical examination of the patient. 'I is important to know the time of onset, timing, frequency, symptom duration, the features of the disease (i.e., wheals only, or wheals and angioedema), characteristics of the lesions (shape, size, site, distribution, and pattern of recurrence), other associated symptoms, familial disease history, and response to previous therapies used. ${ }^{1,12}$

The identification of known potential causes and/or possible triggers (e.g., food, medications, physical stimuli, infections, insect stings, and stressful occurrences) of urticaria is essential. Current drug assumption, especially nonsteroidal anti-inflammatory drugs and angiotensinconverting enzyme inhibitors, should also be established, because these drugs have been associated with the aggravation of pre-existing CSU. ' Food avoidance with elimination diets is not helpful for CSU, while alcohol should be sidestepped because it can significantly exacerbate this condition. ${ }^{12}$

The EAACl/GA ${ }^{2} L E N / E D F / W A O$ guideline recommended laboratory tests such as differential blood count, erythrocyte sedimentation rate, and C-reactive protein.' Furthermore, concomitant autoimmune disorders, thyroid dysfunction, and acute or chronic bacterial (e.g., Helicobacter pylori), viral (e.g., hepatitis virus), parasitic (e.g., Anisakis simplex), or fungal infections need to be investigated. ${ }^{1}$ Screening for neoplastic diseases is not recommended but, if there are atypical features, assessment of serum tryptase, complement levels, and serum protein electrophoresis should be considered and a skin biopsy can be performed.1.12

Recent studies have highlighted that CSU may in some cases be associated with elevated BMI, obesity, diabetes, hyperlipidaemia (high levels of serum total cholesterol, triglycerides, low density lipoprotein, and decreased high density lipoprotein), arterial hypertension, metabolic syndrome, and gout. ${ }^{28,29}$

Differential diagnoses from other conditions in which wheals and angioedema can occur, such as exercise-induced anaphylaxis, autoinflammatory syndromes, urticaria pigmentosa, urticarial vasculitis, or hereditary angioedema, are made clinically. 
Several biomarkers have been investigated in association with CSU activity. Currently, the autologous serum skin test (ASST) and the basophil activation test (BAT) are the most commonly available auto-antibodies screening tests. ${ }^{1}$ ASST is a relatively simple in vivo nonspecific screening test in which the autologous serum is injected back into the patients' skin intradermally to evaluate serum auto-reactivity, mostly due to any type of endogenous proinflammatory or wheal-inducing factors. ${ }^{30}$ A positive ASST has been associated with prolonged disease, which is poorly responsive to routine therapy, and related to a delayed response to omalizumab.. ${ }^{31}$ BAT is an in vitro test that assesses the histamine upregulation or release of activation markers of donor basophils following stimulation from CSU patients' serum; 32 therefore, it helps to co-assess disease activity in CSU patients and a negative BAT is correlated with a better response to omalizumab. ${ }^{33}$ Indirect BAT is a safe and reliable diagnostic tool which is also helpful in monitoring treatment, however it is usually not routinely available in daily clinical practice. ${ }^{32,34-36}$ Another test proposed by Asero et al. ${ }^{37}$ is the autologous plasma skin test (APST). Although the APST cannot be considered a screening test for histamine-releasing autoantibodies, it has recently been shown to a have a greater positive predictive value than ASST and has been correlated with antinuclear antibody positivity and angioedema. ${ }^{38}$

Moreover, D-dimer is related to disease activity in CSU patients due to the activation of the coagulation cascade and it seems to be the most promising biomarker. ${ }^{25,26}$ This observation was confirmed by Kolkhir et al., ${ }^{39}$ who suggested that the evaluation of not only D-dimer but also fibrinogen, C-reactive protein, and erythrocyte sedimentation rate should be considered before starting treatment, because high levels of these markers may predict an unsatisfactory therapeutic response.

However, none of these biomarkers are currently implemented routinely in clinical practice. The still low level of evidence to support the available biomarkers is probably due to the wide variability and heterogeneity in the data collected from the published studies, which often show differences in methodology, design, selection of patient populations, and/or data analysis.
CSU patient management begins with the compilation of patient-reported scoring. ${ }^{40}$ The most frequently utilised scoring system is the 7-day Urticaria Activity Score (UAS7), 1,40 The UAS7 is based on the patient self-assessment of key urticaria signs and symptoms (wheals: $0=$ none; $1=$ mild $[<20$ wheals $/ 24 \mathrm{~h}] ; 2=$ moderate [20-50 wheals $/ 24 \mathrm{~h}] ; 3=$ intense $[>50$ wheals $/ 24$ h or large confluent areas of wheals] and pruritus: $0=$ none; 1 = mild [present but not troublesome]; $2=$ moderate [troublesome but does not interfere with sleep]; 3 = severe [sufficiently troublesome to interfere with normal daily activity or sleep]) once a day for 1 week.

The UAS7 is the sum of the recorded scores over the period of 7 consecutive days, so disease activity and eventually response to treatment can be determined. The sum of score is 0-6 for each day with a maximum of 42 if summarised for a week. Additionally, for patients with recurrent angioedema, the $\mathrm{EAACl} / \mathrm{GA}^{2} \mathrm{LEN} /$ EDF/WAO guideline also suggested the use of the Angioedema Activity Score (AAS). 'The AAS consists of five items regarding the characteristics of angioedema to have occurred in previous 24 hours. ${ }^{41} \mathrm{~A}$ score between $\mathrm{O}$ and 3 is assigned to every answer field. The question scores are added up to produce a daily score. Daily AAS can be summed to give 7-day scores, 4-week scores, and 12-week scores. ${ }^{41}$ The minimum and maximum possible AAS scores are 0-15 (daily), 0-105, O-420, and 0-1,260, respectively.

To evaluate the impact of urticaria on patients, the Urticaria Control Test that assesses patient's disease status (the cut-off value for a well-controlled disease is 12 of 16 possible points), and specific disease quality of life questionnaires (the Chronic Urticaria-Quality of Life Questionnaire [CU-Q2oL] and AngioedemaQuality of Life Questionnaire [AE-QoL]) can also be used., ${ }^{1,40}$

\section{TREATMENT}

The aim of pharmacological treatment is to obtain complete symptom relief. EAACl/ GA²LEN/EDF/WAO guideline suggests regular administration of second-generation, nonsedating, nonimpairing H1-receptor antihistamines as first-line symptomatic treatment for urticaria because of their good safety profile.' Compared 
to the first-generation antihistamines, these antihistamines have greater receptor specificity, lower penetration of the blood-brain barrier, and are less likely to cause drowsiness or psychomotor impairment. ${ }^{10,42}$ First-generation antihistamines should therefore be avoided due to their sedating, impairing, and anticholinergic side effects, while H2-receptor blockers are not felt to be of benefit in the treatment of urticaria. ${ }^{43}$

In nonresponders (adult or paediatric patients), the second-line treatment is the up-dosing of the second-generation $\mathrm{H} 1$-receptor antihistamines by as much as 4-fold. The leukotriene receptor antagonists, in particular montelukast, can be used as an add-on to second-line treatment in $\mathrm{H1}$-antihistamine refractory $\mathrm{CSU}$, but their administration is not recommended by the EAACI/GA²LEN/EDF/WAO guideline.

For patients (aged 12 years and older) with CSU who have not responded to four-times the standard dose of second-generation H1-receptor antihistamines, omalizumab, a humanised monoclonal anti-IgE antibody, as add-on therapy is now considered the third-line treatment. Omalizumab was the first biologic agent approved by the U.S. Food and Drug Administration (FDA) for CSU. This drug has been widely proven to be very effective and well-tolerated in patients with antihistamine-refractory CSU. ${ }^{1}$ Omalizumab binds to free $\operatorname{lgE}$ at the fragment crystallisable region (Fc region) preventing interaction with FceRI receptor on mast cells and basophils. However, the exact mechanisms for the therapeutic effects of this drug for CSU remain unclear. Both 150 and $300 \mathrm{mg}$ of omalizumab injected subcutaneously every 4 weeks have been shown to be effective for refractory CSU (the licensed dosage in Europe is $300 \mathrm{mg}$, while in the USA this is either 150 or $300 \mathrm{mg}){ }^{40}$ Dosage is currently recommended independently of total serum IgE count or patient body weight. Instead, only the dosage of $300 \mathrm{mg}$ every 4 weeks has been proven to be effective in case of angioedema. ${ }^{44}$

Alternative dosages (off-label) of omalizumab have been used successfully in refractory CSU and reported in small case series: low doses of omalizumab ( $150 \mathrm{mg}$ every 4 weeks) for long-term management of patients following initial therapy, and high dosages (450 or $600 \mathrm{mg}$ every 4 weeks) for partial or nonresponders. ${ }^{40}$ Omalizumab nonresponders are considered those with no symptom control after four doses of omalizumab 300 mg every 4 weeks, because the response rate is similar to placebo after this 16-week period. ${ }^{45}$ To date, strategies or duration of omalizumab therapy, once disease control is optimised, has not found a universal agreement.

For all patients with wheals and angioedema, corticosteroid administration, in particular prednisone (dosage 0.3-0.5 mg/kg/day), over restricted periods of time (typically $\leq 10$ days) can be prescribed as add-on treatment.

Finally, the fourth-line treatment (if there is no response to omalizumab within 6 months, or if the condition is intolerable) is cyclosporine $A$ (CsA). CsA inhibits the production of IL-2, IL-3, IL4, and TNF-a in lymphocytes and inhibits the IgEmediated release of histamine from mast cells. High doses of CsA and long duration treatment are associated with adverse events such as abdominal pain, nausea, vomiting, paresthesia, headache, hirsutism, elevated serum creatinine, and hypertension; however, these effects resolve after reducing dose. ${ }^{46}$ Nevertheless, CsA should be avoided in patients with chronic kidney disease or poorly controlled hypertension. CsA at the dose of 3-5 mg/ $\mathrm{kg} /$ day has been shown in small, double-blind, randomised controlled trials to be effective in patients with CSU who do not adequately respond to antihistamines. ${ }^{47,48}$ During CsA treatment, given the significant side effects, the blood pressure, renal function, and serum cyclosporine levels should be monitored regularly. Simplified stepwise algorithm for the treatment of CSU adapted from the EAACl/GA ${ }^{2}$ LEN/EDF/ WAO guideline is summarised in Figure 2.

\section{OTHER THERAPEUTIC OPTIONS (TABLE 1)}

Phototherapy reduces the number of cutaneous mast cells in the superficial dermis and it has been used for the treatment of antihistamine-refractory corticosteroid-dependent CSU in combination with antihistamines for periods between 1 and 3 months, but published data are still limited. ${ }^{49,50}$ Recently, 50 patients with steroid-dependent CSU were randomised to receive either narrowband ultraviolet B (NB-UVB) or psoralen plus ultraviolet A phototherapy in addition to licensed doses of antihistamines for 90 days. ${ }^{51}$ The reduction in symptoms was maintained in both groups during 
a 90-day post-treatment observation period, but NB-UVB phototherapy was found to be statistically better than psoralen plus ultraviolet $A$ at different time points. Bishnoi et al. ${ }^{51}$ proposed the combination of antihistamines with NB-UVB prior to third-line treatment with omalizumab.

Intravenous Ig (IVIg) has been used successfully for the treatment of antihistaminerefractory CSU due to its immunoregulatory effects. Its mechanisms for the immune modulation and anti-inflammatory actions include Fc receptor blockade (IVIg blocks FceRI activity on mast cells, which prevents IgE binding and degranulation), inhibition of complement deposition, enhancement of regulatory $T$ cells, inhibition or neutralisation of cytokines and growth factors, accelerated clearance of autoantibodies, modulation of adhesion molecules and cell receptors, and activation of regulatory macrophages through the FcyRllb receptor. ${ }^{52}$ However, due to the high cost, prolonged infusion times, and limited data on efficacy, the clinical use of IVIg is somewhat limited and alternative biologic agents should be considered.

CSU patients have been proven to have an upregulated TNF-a in the lesional and nonlesional skin. ${ }^{53}$ TNF-a inhibitors (etanercept, infliximab, and adalimumab) have been reported to be effective in the treatment of CSU and may be a therapeutic option to those who have failed other alternative therapies.53,54 However, no head-to-head studies have been performed to date and these drugs may be limited by their increased risk for infections, including tuberculosis and fungal infections, along with an increased risk for lymphomas and other malignancies.

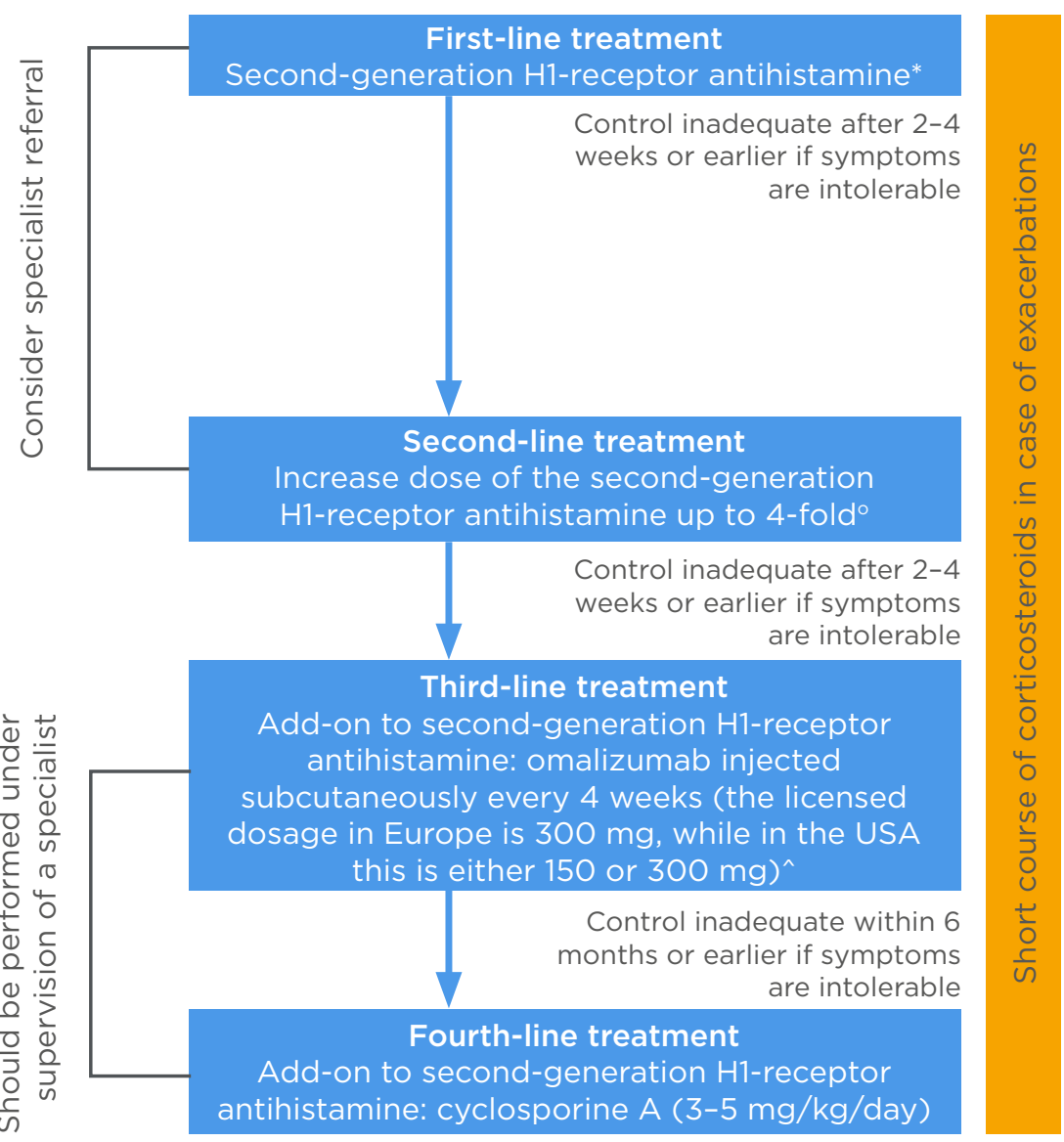

*Second-generation H1-receptor antihistamines commonly used:

- Bilastine: 20 mg daily (adult); not currently indicated for children under 12 years of age. - Certirizine: 10-20 mg daily (adult); 5-10 mL (1-2 teaspoons) daily (paediatric patient).

- Desloratadine: 5 mg daily (adult); 2.5-5 mL (0.5-1 teaspoon) daily (paediatric patient).

- Fexofenadine: 120 mg daily (adult); not currently indicated for children under 12 years of age. - Loratadine: 10 mg daily (adult); 5-10 mL (1-2 teaspoons) daily (paediatric patient).

- Rupatadine: 10 mg daily (adult); 5-10 mL (1-2 teaspoons) daily (paediatric patient).

-The leukotriene receptor antagonists (especially montelukast) can be used as an add-on therapy but is not recommended by the EAACI/GA ${ }^{2} \mathrm{LEN} /$ EDF/WAO guideline

${ }^{\wedge}$ Only the dosage of $300 \mathrm{mg}$ has been proven to be effective in case of angioedema

Figure 2: Simplified stepwise algorithm for the treatment of urticaria adapted from the EAACI/GA ${ }^{2} L E N / E D F / W A O$ guideline 2018. 
Table 1: Other therapeutic options in chronic spontaneous urticaria.

\begin{tabular}{|c|c|c|}
\hline Treatment & $\begin{array}{l}\text { Mechanism of action in chronic } \\
\text { spontaneous urticaria }\end{array}$ & $\begin{array}{l}\text { Dosing/frequency in chronic } \\
\text { spontaneous urticaria }\end{array}$ \\
\hline Phototherapy & $\begin{array}{l}\text { Reduces the number of cutaneous } \\
\text { mast cells in the superficial dermis }\end{array}$ & $\begin{array}{l}\text { Narrowband ultraviolet B three times } \\
\text { weekly in addition to licensed doses } \\
\text { of antihistamines for } 3 \text { months }\end{array}$ \\
\hline Intravenous Ig & $\begin{array}{l}\text { Blocks FceRI activity on mast cells, } \\
\text { which prevents IgE binding and } \\
\text { degranulation and may decrease } \\
\text { B-cell autoantibody production }\end{array}$ & $\begin{array}{l}0.4 \mathrm{mg} / \mathrm{kg} / \text { day intravenous infusion } \\
\text { for } 5 \text { days every } 4-6 \text { weeks but lower } \\
\text { doses ( } 0.15 \mathrm{mg} / \mathrm{kg} / \text { day) have also } \\
\text { been explored with good results }\end{array}$ \\
\hline TNF-a inhibitors & $\begin{array}{l}\text { Block upregulation of TNF-a } \\
\text { production in the lesional and } \\
\text { nonlesional skin }\end{array}$ & $\begin{array}{l}\text { Etanercept } 50 \text { mg injection } \\
\text { subcutaneous once weekly, infliximab } \\
5 \mathrm{mg} / \mathrm{kg} \text { intravenous infusion every } \\
8 \text { weeks, and adalimumab } 40 \mathrm{mg} \\
\text { injection subcutaneous every } \\
2 \text { weeks }\end{array}$ \\
\hline Rituximab & $\begin{array}{l}\text { B-cell depletion via complement and } \\
\text { antibody-dependent cytotoxicity } \\
\text { results in decreased circulating } \\
\text { autoantibody levels }\end{array}$ & $\begin{array}{l}\text { Rituximab } 375 \text { mg/m2 intravenous } \\
\text { infusion once weekly for } 4 \text { weeks }\end{array}$ \\
\hline Ligelizumab & $\begin{array}{l}\text { Similar in function to omalizumab, } \\
\text { but produces a greater and longer } \\
\text { suppression of free IgE and IgE on } \\
\text { the surface of basophils }\end{array}$ & $\begin{array}{l}\text { Ligelizumab } 72 \text { mg or } 240 \text { mg } \\
\text { injection subcutaneous every } 4 \\
\text { weeks }\end{array}$ \\
\hline Bruton tyrosine kinase inhibitor & Unknown & $\begin{array}{l}\text { GDC-0853 oral administration twice } \\
\text { daily for a total of } 56 \text { days }\end{array}$ \\
\hline Spleen tyrosine kinase inhibitor & $\begin{array}{l}\text { Blocks upregulation of transcription } \\
\text { factors responsible for the } \\
\text { synthesis and degranulation of } \\
\text { proinflammatory mediators }\end{array}$ & $\begin{array}{l}\text { GSK2646264 topical application for } \\
28 \text { days }\end{array}$ \\
\hline IL-1 inhibitors & $\begin{array}{l}\text { Inhibition of IL-1及 may modify the } \\
\text { clinical course of urticarial lesions }\end{array}$ & $\begin{array}{l}\text { Canakinumab } 150 \text { mg injection } \\
\text { subcutaneous every } 8 \text { weeks, } \\
\text { Anakinra } 100 \text { mg injection } \\
\text { subcutaneous once a day }\end{array}$ \\
\hline $\begin{array}{l}\text { Prostaglandin D2 receptor } \\
\text { antagonist }\end{array}$ & $\begin{array}{l}\text { Inhibition of chemoattractant } \\
\text { receptor homologous molecule } \\
\text { expressed on Th2 cells could reduce } \\
\text { the frequency and severity of } \\
\text { urticarial lesions because of its anti- } \\
\text { inflammatory properties }\end{array}$ & $\begin{array}{l}\text { AZD1981 } 40 \text { mg oral administration } \\
\text { three times daily for a total of } 7 \text { days }\end{array}$ \\
\hline
\end{tabular}

Rituximab, a mouse-human chimeric anti-CD20 monoclonal antibody, induces B-cell depletion by targeting the CD2O antigen on the $\mathrm{B}$ lymphocytes. This mechanism results in inhibition of autoantibody production and some promising results have been demonstrated in patients with CSU; 55 however, given the lack of randomised, double-blind, placebo-controlled trials, rituximab is not licensed for the treatment of antihistamine-refractory CSU.

Future therapeutic options currently under investigation include new-generation biological drugs. Ligelizumab, a humanised IgG1k monoclonal antibody targeting the third heavy chain constant region domain of lgE, is similar in function to omalizumab, but has been proven to bind free IgE with greater affinity. ${ }^{56}$ A Phase IIB dose-finding trial ${ }^{57}$ evaluated the efficacy and safety of this drug compared with placebo and omalizumab, showing complete control of symptoms in a higher percentage of patients with ligelizumab therapy of $72 \mathrm{mg}$ or $240 \mathrm{mg} .^{58}$ Currently, an extension study ${ }^{59}$ is investigating the long-term safety of this drug in CSU patients who completed the trial, remained in the followup period for at least 32 weeks, and had an active disease (UAS7 $\geq 12$ ). 
Another humanised IgG1 monoclonal antibody is quilizumab, which targets the $M 1$ prime segment of membrane-expressed IgE resulting in diminished IgE-switched B cells and plasmablasts. The effects appeared to last up to 6 months after completion of therapy, ${ }^{60}$ however, further development of this drug has been discontinued.

Other agents are currently under experimentation in clinical trials. Bruton tyrosine kinase is a nonreceptor tyrosine kinase that transmits signals crucial for B-cell development and its genetic deletion causes B-cell immunodeficiency. ${ }^{61}$ Although the role of B cells in urticaria is not well understood, it is believed that bruton tyrosine kinase inhibitors could potentially play a role in refractory CSU management. GDC-0853, a bruton tyrosine kinase inhibitor, is currently under investigation in a Phase IIA multicentre, randomised, double-blind, placebo-controlled pilot study ${ }^{62}$ that is evaluating the efficacy, safety, and pharmacodynamics of this drug compared with placebo in individuals with anthistaminerefractory CSU.

Spleen tyrosine kinase upregulates transcription factors that are responsible for the synthesis and degranulation of proinflammatory mediators and its expression increases in certain subsets of patients affected by CSU. ${ }^{63-65}$ GSK2646264, a topical spleen tyrosine kinase inhibitor, is currently being tested in a randomised, doubleblind, single and repeat ascending trial in order to determine its efficacy in patients with CSU and cold urticaria. ${ }^{66}$

Inhibition of IL-1及 may modify the clinical course of urticarial lesions in patients affected by CSU and various studies are underway in order to elucidate the role of IL-1 inhibitors in CSU. ${ }^{67}$ Canakinumab, a fully human anti-IL-1 $1 \beta$ antibody, is currently under investigation in a Phase II randomised, double-blind, placebo-controlled, single-centre study evaluating the use of this drug compared with placebo in CSU patients. ${ }^{68}$ Finally, inhibition of chemoattractant receptorhomologous molecule expressed on $\mathrm{T}_{\mathrm{H}} 2$ cells could reduce the frequency and severity of urticarial lesions because of its anti-inflammatory properties. CSU patient eosinophils overexpress this prostaglandin D2 receptor. ${ }^{69}$ A Phase IIA, randomised, placebo-controlled, double-blind study is evaluating the efficacy of AZD1981, a prostaglandin D2 receptor antagonist, as a potential therapeutic option in CSU. ${ }^{70}$

Further investigations are needed for identifying strategies for the prevention and symptomatic treatment of $\mathrm{CSU}$, identification of the best therapy, and development of new drugs. Moreover, the exploration of novel therapeutic targets can help to better understand the aetiopathogenesis of the disease.

\section{CONCLUSIONS}

There is currently a low level of evidence on the exact pathological mechanism in CSU, and as a result clinical and diagnostic indications have not recently changed. New-generation treatment options should be available in the near future and seem promising. Future studies should investigate personalised treatment, with recommended dosages considering disease severity and treatment responsiveness.

\section{References}

1. Zuberier $\mathrm{T}$ et al. The $\mathrm{EAACl} /$ GA ${ }^{2} L E N / E D F / W A O$ guideline for the definition, classification, diagnosis and management of urticaria. Allergy. 2018;73(7):1393-414.

2. Pasaoglu G et al. Psychological status of patients with chronic urticaria. J Dermatol. 2006;33(11):765-71.

3. Engine $B$ et al. The levels of depression, anxiety and quality of life in patients with chronic idiopathic urticaria. J Eur Acad Dermatol Venereol. 2008;22(1):36-40.
4. Staubach P et al. High prevalence of mental disorders and emotiona distress in patients with chronic spontaneous urticaria. Acta Derm Venereol. 2011;91(5):557-61.

5. Radonjic-Hoesli S et al. Urticaria and angioedema: an update on classification and pathogenesis. Clin Rev Allergy Immunol. 2018;54(1):88101.

6. Powell RJ et al. BSACl guideline for the management of chronic urticaria and angioedema. Clin Exp Allergy.
2015;45(3):547-65.

7. Magen E et al. The clinical and laboratory characteristics of acute spontaneous urticaria and its progression to chronic spontaneous urticaria. Allergy Asthma Proc. 2016;37(5):394-9.

8. Bernstein JA et al. The diagnosis and management of acute and chronic urticaria: 2014 update. J Allergy Clin Immunol. 2014;133(5):1270-7.

9. Balp MM et al. Prevalence and 
clinical characteristics of chronic spontaneous urticaria in pediatric patients. Pediatr Allergy Immunol. 2018;29(6):630-6.

10. Kim BR et al. Epidemiology and comorbidities of patients with chronic urticaria in Korea: a nationwide population-based study. J Dermatol. 2018;45(1):10-6.

11. Maurer $M$ et al. Unmet clinical needs in chronic spontaneous urticaria. A GA ${ }^{2} L E N$ task force report. Allergy Eur J Allergy Clin Immunol. 2011;66(3):317-30.

12. Kanani A et al. Urticaria and angioedema. Allergy Asthma Clin Immunol. 2018;14(Suppl 2):59.

13. Zhao ZT et al. Omalizumab for the treatment of chronic spontaneous urticaria: A meta-analysis of randomized clinical trials. J Allergy Clin Immunol. 2016;137(6):1742-50.

14. Confino-Cohen $\mathrm{R}$ et al. Chronic urticaria and autoimmunity: associations found in a large population study. J Allergy Clin Immunol. 2012;129(5):1307-13.

15. Bracken SJ et al. Autoimmune theories of chronic spontaneous urticaria. Front Immunol. 2019;10:627.

16. Kaplan AP, Greaves M. Pathogenesis of chronic urticaria. Clin Exp Allergy. 2009;39(6):777-87

17. Zuberbier T et al. Enhanced $\mathrm{P}$-selectin expression in chronic and dermographic urticaria. Int Arch Allergy Immunol. 1997;114(1):86-9.

18. Kay $A B$ et al. Elevations in vascular markers and eosinophils in chronic spontaneous urticarial wheals with low level persistence in uninvolved skin. Br J Dermatol. 2014;171(3):505-11.

19. Zuberbier $T$ et al. Histamine releasability of basophils and skin mast cells in chronic urticaria. Allergy. 1996;51(1):24-8.

20. Grattan CE et al. Blood basophil numbers in chronic ordinary urticaria and healthy controls: diurnal variation, influence of loratadine and prednisolone and relationship to disease activity. Clin Exp Allergy. 2003;33(3):337-41.

21. Eckman JA et al. Basophil phenotypes in chronic idiopathic urticaria in relation to disease activity and autoantibodies. J Invest Dermatol. 2008;128(8):1956-63.

22. Saini SS et al. Effect of omalizumab on blood basophil counts in patients with chronic idiopathic/spontaneous urticaria. J Invest Dermatol. 2017:137(4):958-61.

23. Ulambayar B, Park HS. Anti-TPO IgE autoantibody in chronic urticaria: is it clinically relevant? Allergy Asthma Immunol Res. 2019;11(1):1-3.

24. Gell PGH, Coombs RRA, "The Classification Of Allergic Reactions Underlying Disease", Coombs RRA,
Gell PGH (eds), Clinical Aspects Of Immunology (1963), London: Blackwell, pp. 317-37.

25. Asero R et al. D-dimer plasma levels parallel the clinical response to omalizumab in patients with severe chronic spontaneous urticaria. Int Arch Allergy Immunol. 2017;172(1):404.

26. Asero $\mathrm{R}$ et al. Baseline D-dimer plasma levels correlate with disease activity but not with the response to omalizumab in chronic spontaneous urticaria. Allergy. 2019;74(12):2538.

27. Zbiciak-Nylec $M$ et al. Overweight and obesity may play a role in the pathogenesis of chronic spontaneous urticaria. Clin Exp Dermatol. 2018;43(5):525-8.

28. Shalom $\mathrm{G}$ et al. Chronic urticaria and the metabolic syndrome: a crosssectional community-based study of 11261 patients. J Eur Acad Dermatol Venereol. 2018;32(2):276-81.

29. Maged Amin M, Rushdy M. Hyperlipidemia in association with pro-inflammatory cytokines among chronic spontaneous urticaria: casecontrol study. Eur Ann Allergy Clin Immunol. 2018;50(6):254-61.

30. Gericke J et al. Serum autoreactivity predicts time to response to omalizumab therapy in chronic spontaneous urticaria. J Allergy Clin Immunol. 2017;139(3):1059-61.

31. Kolkhir P et al. C-reactive protein is linked to disease activity, impact, and response to treatment in patients with chronic spontaneous urticaria. Allergy. 2018;73(4):940-8.

32. Curto-Barredo L et al. Basophil activation test identifies the patients with chronic spontaneous urticaria suffering the most active disease. Immun Inflamm Dis. 2016;4(4):441-5.

33. Palacios $T$ et al. Lack of basophi CD203c-upregulating activity as an immunological marker to predict response to treatment with omalizumab in patients with symptomatic chronic urticaria. J Allergy Clin Immunol Pract. 2016;4(3):529-30.

34. labal $\mathrm{K}$ et al. A positive serum basophil histamine release assay is a marker for ciclosporin responsiveness in patients with chronic spontaneous urticaria. Clin Transl Allergy. 2012;2(1):19.

35. Netchiporouk E et al. Positive CD63 basophil activation tests are common in children with chronic spontaneous urticaria and linked to high disease activity. Int Arch Allergy Immunol. 2016:171(2):81-8.

36. Kim Z et al. Basophil markers for identification and activation in the indirect basophil activation test by flow cytometry for diagnosis of autoimmune urticaria. Ann Lab Med. 2016;36(1):28-35.
37. Asero R et al. Plasma of patients with chronic urticaria shows signs of thrombin generation, and its intradermal injection causes wheal-and-flare reactions much more frequently than autologous serum. J Allergy Clin Immunol. 2006;117(5):1113-7.

38. Kumaran MS et al. Autologous serum and plasma skin tests in chronic spontaneous urticaria: a reappraisal. Indian Dermatol Online J. 2017;8(2):94-9.

39. Kolkhir $\mathrm{P}$ et al. CRP, D-dimer, fibrinogen and ESR as predictive markers of response to standard doses of levocetirizine in patients with chronic spontaneous urticaria. Eur Ann Allergy Clin Immunol. 2017:49(4):189-92

40. Mandel VD et al. Omalizumab in chronic spontaneous urticaria refractory to conventional therapy: an italian retrospective clinical analysis with suggestions for long-term maintenance strategies. Dermatol Ther (Heidelb). 2018;8(2):291-301.

41. Weller $\mathrm{K}$ et al. Development, validation and initial results of the Angioedema Activity Score. Allergy. 2013;68(9):1185-92.

42. Ridolo $\mathrm{E}$ et al. Bilastine: new insight into antihistamine treatment. Clin $\mathrm{Mol}$ Allergy. 2015;13(1):1.

43. Fedorowicz Z et al. Histamine H2receptor antagonists for urticaria. Cochrane Database Syst Rev. 2012;(3):CD008596.

44. Maurer $M$ et al. Omalizumab for the treatment of chronic idiopathic or spontaneous urticaria. N Engl J Med. 2013:368(10):924-35.

45. Kaplan A et al. Timing and duration of omalizumab response in patients with chronic idiopathic/spontaneous urticaria. J Allergy Clin Immunol. 2016;137(2):474-81

46. Kulthanan $\mathrm{K}$ et al. Cyclosporine for chronic spontaneous urticaria: a meta-analysis and systematic review. J Allergy Clin Immunol Pract. 2018;6(2):586-99.

47. Grattan CE et al. Randomized doubleblind study of cyclosporin in chronic "idiopathic" urticaria. Br J Dermatol. 2000;143(2):365-72

48. Vena GA et al. Cyclosporine in chronic idiopathic urticaria: a doubleblind, randomized, placebocontrolled trial. J Am Acad Dermatol. 2006;55(4):705-9.

49. Hannuksela M, Kokkonen EL. Ultraviolet light therapy in chronic urticaria. Acta Derm Venereol. 1985;65(5):449-50

50. Engin B et al. Treatment of chronic urticaria with narrowband ultraviolet B phototherapy: a randomized controlled trial. Acta Derm Venereol. 2008;88(3):247-51. 
51. Bishnoi A et al. Phototherapy using narrowband ultraviolet $B$ and psoralen plus ultraviolet $A$ is beneficial in steroid-dependent antihistamine-refractory chronic urticaria: a randomized, prospective observer-blinded comparative study. $\mathrm{Br} J$ Dermatol. 2017;176(1):62-70.

52. Ballow $M$. The lgG molecule as a biological immune response modifier: mechanisms of action of intravenous immune serum globulin in autoimmune and inflammatory disorders. J Allergy Clin Immunol. 2011;127(2):315-23.

53. Hermes B et al. Upregulation of TNFalpha and IL-3 expression in lesional and uninvolved skin in different types of urticaria. J Allergy Clin Immunol. 1999:103(2 Pt 1):307-14.

54. Wilson LH et al. Treatment of refractory chronic urticaria with tumor necrosis factor-alpha inhibitors. J Am Acad Dermatol. 2011;64(69):1221-2.

55. Curto-Barredo L, Giménez-Arnau AM. Treatment of chronic spontaneous urticaria with an inadequate response to H1-antihistamine. G Ital Dermatol Venereol. 2019;154(4):444-56.

56. Arm JP et al. Pharmacokinetics, pharmacodynamics and safety of QGEO31 (ligelizumab), a nove high-affinity anti-IgE antibody, in atopic subjects. Clin Exp Allergy. 2014;44(11):1371-85.

57. Novartis Pharmaceuticals. Dosefinding Study of QGEO31 as add- on Therapy to Evaluate Efficacy and Safety in Patients With CSU NCTO2477332. https://clinicaltrials. gov/ct2/show/NCTO2477332

58. Maurer $M$ et al. Ligelizumab for chronic spontaneous urticaria. N Engl J Med. 2019;381(14):1321-32.

59. Novartis Pharamceuticals. A Safety Extension Study to Evaluate the Long-term Safety of QGEO31 in Chronic Spontaneous Urticaria (CSU) Patients. NCTO2649218. https://clinicaltrials.gov/ct2/show/ NCT02649218.

60. Gauvreau GM et al. Targeting membrane-expressed IgE B cell receptor with an antibody to the $\mathrm{M} 1$ prime epitope reduces IgE production. Sci Transl Med. 2014;6(243):243ra285

61. Burger JA. Bruton's tyrosine kinase (BTK) in clinical trials. Curr Hematol Malig Rep. 2014;9(1):44-9.

62. Genetech, Inc. Efficacy and Safety of GDC-0853 in Participants With Refractory Chronic Spontaneous Urticaria (CSU). NCT03137069. https://clinicaltrials.gov/ct2/show/ NCT03137069.

63. Saini SS et al. Cultured peripheral blood mast cells from chronic idiopathic urticaria patients spontaneously degranulate upon IgE sensitization: relationship to expression of Syk and SHIP-2. Clin Immunol. 2009;132(3):342-8.

64. Altman K, Chang C. Pathogenic intracellular and autoimmune mechanisms in urticaria and angioedema. Clin Rev Allergy Immunol. 2013;45(1):47-62.

65. Vonakis BM et al. Src homology 2 domain-containing inositol 5' phosphatase is negatively associated with histamine release to human recombinant histamine-releasing factor in human basophils. J Allergy Clin Immunol. 2001;108(5):822-31.

66. GlaxoSmithKline. Study to Investigate Safety, Tolerability, Pharmacodynamics and Pharmacokinetics of GSK2646264. NCTO2424799. https://clinicaltrials. gov/ct2/show/NCTO2424799.

67. Joshi S, Khan DA. The expanding field of biologics in the management of chronic urticaria. J Allergy Clin Immunol Pract. 2017;5(6):1489-99.

68. University of Zurich. Efficacy Study of Canakinumab to Treat Urticaria (URTICANA). NCTO1635127. https://clinicaltrials.gov/ct2/show/ NCT01635127.

69. Yahara $\mathrm{H}$ et al. Increased expression of CRTH2 on eosinophils in allergic skin diseases. J Eur Acad Dermatol Venereol. 2010;24(1):75-6.

70. Johns Hopkins University. Efficacy and Safety of Chemoattractant Receptor-homologous Molecule Expressed on T Helper Type 2 (CRTh2) Antagonist AZD1981 in Chronic Idiopathic Urticaria (CIU) Antihistamines. NCTO2031679. https://clinicaltrials.gov/ct2/show/ NCTO2031679. 